\title{
Comparison of functioning and health-related quality of life among patients with HTLV-1, HIV, and HIV-HTLV-1-coinfection
}

\author{
Cleyde Sheyla Chachaqui Marconi ${ }^{[1],[2], ~ L i l i a n e ~ L i n s-K u s t e r e r ~}{ }^{[1],[2],[3],}$ \\ Carlos Brites ${ }^{[1],[2],[3]}$ and Mansueto Gomes-Neto ${ }^{[2],[3],[4]}$
}

\author{
[1]. Universidade Federal da Bahia, Faculdade de Medicina, Salvador, BA, Brasil. \\ [2]. Universidade Federal da Bahia, Programa de Pós-Graduação em Medicina e Saúde, Salvador, BA, Brasil. \\ [3]. Complexo Hospitalar Universitário Professor Edgard Santos, Laboratório de Pesquisa em Doenças Infecciosas, Salvador, BA, Brasil. \\ [4]. Universidade Federal da Bahia, Departamento de Fisioterapia, Salvador, BA, Brasil.
}

\begin{abstract}
Introduction: Human immunodeficiency virus (HIV) and human T-cell leukemia virus-1 (HTLV-1) viruses are associated with a high global burden of disease, and coinfection is a frequently reported event. We aimed to compare the functioning and health-related quality of life (HRQoL) of patients infected with HTLV-1, HIV, and HIV-HTLV-1. Methods: We conducted a cross-sectional study of patients older than 18 years who had an HTLV-1 infection (Group A), HIV infection (Group B), or HIV-HTLV-1 coinfection (Group C). The functioning profiles were evaluated using handgrip strength, Berg balance scale (BBS), timed "up and go" (TUG) test, and 5-m walk test (m/s). We used the World Health Organization Disability Assessment Schedule (WHODAS 2.0) questionnaire to measure disability. The HRQoL was evaluated using a 36-item short-form health survey. For data with parametric and non-parametric distribution, we used analysis of variance with Bonferroni correction and the Kruskal-Wallis test, followed by Dunn's pairwise tests with Bonferroni correction. Results: We enrolled 68 patients in Group A, 39 in Group B, and 29 in Group C. The scores for handgrip strength, BBS, TUG test, all the WHODAS domains, and HRQoL were poorer for Groups A and C than for Group B. Conclusions: Compared to patients with HIV infection, those with HIVHTLV-1 coinfection and HTLV-1 infection had poor functioning and HRQoL scores. HTLV-1 infection was associated with reduced functioning and HRQoL in patients with a single HTLV-1 infection and HIV-HTLV-1 coinfection.
\end{abstract}

Keywords: HIV-1. HTLV-1. Coinfection. Physical functional performance. Health-related quality of life.

\section{INTRODUCTION}

The human T-cell leukemia virus-1 (HTLV-1) is the first human retrovirus to be identified; it is associated with chronic, persistent infection of T cells ${ }^{1}$. HTLV-1 and human immunodeficiency virus (HIV) share the same route of transmission and are tropic to $\mathrm{T}$ lymphocytes, so coinfection with both agents is a frequent occurrence in endemic areas ${ }^{2,3}$. HIV-HTLV-1 coinfection is commonly reported in South America, the Caribbean, and Africa ${ }^{3}$.

In Bahia, Brazil, HIV-HTLV-1 coinfection is associated with increased morbidity and lower survival than HIV monoinfection ${ }^{4}$.

\footnotetext{
Corresponding author: Prof. Mansueto Gomes-Neto.

e-mail: mansueto.neto@ufba.br

(iD) https://orcid.org/0000-0002-0717-9694

Received 23 October 2020

Accepted 19 February 2021
}

Brites et al. ${ }^{2}$ reported that patients with HIV-HTLV-1 infection have higher CD4 T-cell counts than those with HIV monoinfection although this did not translate into a clinical benefit.

Both HIV and HTLV-1 infections are considered chronic diseases associated with physical impairment, disabilities, and poor health-related quality of life (HRQoL) ${ }^{5-7}$. In a recent systematic review, San-Martin et al. ${ }^{8}$ evaluated the pain characteristics of patients with HTLV-1 infection and reported that chronic pain was negatively associated with quality of life $^{7}$. In addition, other studies have shown that HIV-related disabilities are associated with decrease in aerobic capacity, HRQoL, and daily activities ${ }^{6,9}$.

Infection with HTLH or HIV can negatively impact the functionality and HRQoL of the patients. Although patients with HIV-HTLV-1 coinfection may experience a greater reduction in functionality and HRQoL than those with monoinfections, few studies have explored the functioning and HRQoL characteristics 
of patient populations with HIV-HTLV-1 coinfection ${ }^{10}$. The goal of this study was to compare the functioning and HRQoL of patients with HTLV-1 or HIV monoinfection and HIV-HTLV-1 coinfection.

\section{METHODS}

\section{Study Population}

We conducted a cross-sectional study of three groups of patients who were examined consecutively and followed regularly at the Infectious Diseases Outpatient Clinic at the Hospital Complex Professor Edgard Santos of the Federal University of Bahia, Salvador, Brazil. Data on the clinical and sociodemographic characteristics of the infected patients were collected from October 2017 to November 2018. The inclusion criteria for the three groups were age $\geq 18$ years and confirmed infection with HIV and/or HTLV-1. Group A consisted of patients with HTLV-1 infection, Group B, of patients with HIV infection, and Group C, of those with HIV-HTLV-1 coinfection. We reviewed the medical records of 156 individuals in Group A (HTLV blot 2.4, Genelab, Singapore) whose diagnosis of HTLV-1 infection was confirmed by western blot; we also ensured that these patients tested negative for HIV-1 infection. Patients with HTLV-1 associated myelopathy/tropical spastic paraparesis (HAM/TSP), Adult T-cell leukemia-lymphoma (ATLL), or other neurologic diseases confirmed by a specialist; individuals with a family history of spastic paraparesis; those with spinal cord lesions; and those currently undergoing treatment with antiretroviral (ARV) drugs were excluded. For Group B (HIV), the specific criteria were as follows: presence of HIV infection confirmed by western blot or polymerase chain reaction test, presence of undetectable HIV-1 plasma viral loads for at least 12 months, and currently on stable ARV therapy. The exclusion criteria were as follows: presence of active opportunistic infections, other diagnosed neurologic diseases, or neoplasia; treatment-naive status; and currently enrolled in clinical trials. For Group C (HIV-HTLV-1), the specific inclusion criteria were as follows: confirmed diagnoses of HTLV-1 and HIV according to the same criteria for Groups A and B, currently on stable ARV therapy, and HIV-1 RNA plasma viral loads of $<40$ copies $/ \mathrm{mL}$. The exclusion criteria were as follows: laboratory-confirmed HTLV-2 and presence of any of the exclusion criteria listed for Groups A and B.

\section{Data collection}

We collected patient data related to medical history, sociodemographic characteristics, and HRQoL. Functioning was evaluated by measuring muscle strength, pain, walking speed, balance performance, and mobility. We used the World Health Organization Disability Assessment Schedule (WHODAS 2.0), which is a generic assessment instrument developed by the WHO that provides a standardized method for measuring health and disability ${ }^{11}$. A trained researcher performed all the test procedures.

The patients were categorized according the following variables: sex, skin color/race/ethnicity, marital status, educational status, family income, current smoking, alcohol consumption, physical activity level, body mass index, and comorbidities. We calculated the Charlson comorbidity index (CCI) to assess the severity of comorbid diseases using the following parameters for score interpretation: mild (CCI scores of 1-2), moderate (3-4), and severe $(\geq 5)^{12}$.
We measured the height, body weight, and waist circumference of all the patients. Body mass index (BMI) was calculated by dividing body weight by height in meters squared $\left(\mathrm{kg} / \mathrm{m}^{2}\right)$. Handgrip strength was measured using a dynamometer according to the protocol of the American Society of Hand Therapists ${ }^{13}$. The individual's dominant hand was subjected to the test, and the best of the three measurements, with 1-minute intervals between tests, was recorded ${ }^{13}$.

To assess the walking speed, the 5-m walk test (5MWT) was performed in a 10-m-long straight corridor (Wilson et al., 2013). The Berg balance scale (BBS) was used to assess functional balance performance. The BBS is based on 14 common items of daily life. The score for each scale item ranges from 0 to 4 , and the maximum score is $56^{14}$.

We used the Brief Pain Inventory (BPI) to measure the sensory and reactive dimensions of pain ${ }^{15}$. The numerical rating scales ranging from 0 to 10 were used for each item. Pain severity scales range from 0 (no pain) to 10 (most severe pain a person can imagine). The interference measures were 0 for no interference and 10 for complete interference ${ }^{15}$. The timed up-and-go (TUG) test was used to assess patient mobility. Scores $<10 \mathrm{~s}$ were considered normal, whereas scores $<20 \mathrm{~s}$ and $<30 \mathrm{~s}$ reflected good and impaired mobility, respectively ${ }^{16}$.

We used the 36-item Short-Form Health Survey (SF-36v2), validated in Brazil ${ }^{17}$, to assess the HRQoL. The instrument measures eight domains: physical functioning $(\mathrm{PF})$, role limitations due to physical problems (RP), bodily pain (BP), general health perceptions $(\mathrm{GH})$, vitality (VT), social functioning (SF), role limitations due to emotional problems (RE), and mental health $(\mathrm{MH})$, generating two summary scores: the physical component summary (PCS) and mental component summary (MCS $)^{17}$. We used PROCoREv1.3 to obtain the norm-based scores, enabling comparisons between domains, since all scores were adjusted to a mean of 50 and a standard deviation of 10 . The license agreement for the program ended with QM038920.

We used the WHODAS 2.0 questionnaire to measure health and disability ${ }^{12}$. This tool was developed by the International Classification of Functioning, Disability and Health (ICF) ${ }^{18}$ and captures the level of functioning in six domains of life: cognition (understanding and communicating), mobility (moving and getting around), self-care (attending to one's hygiene, dressing, eating, and living alone), getting along (interacting with other people), life activities (domestic responsibilities, leisure, work, and school), and participation (joining in community activities and participating in society) ${ }^{11}$. The scoring system had three steps: the items in each domain were summed and weighted; then, all six domain scores were summed, and finally, the summary score was converted into a metric ranging from 0 to 100 (where 0 indicates no disability and 100 indicates full disability ${ }^{11}$.

\section{Statistical analysis}

The descriptive statistics used were frequency for categorical variables and mean and standard deviation for continuous variables. We performed the Shapiro-Wilk test to evaluate normality and 
Levene's test to determine the homogeneity of variance for all variables. Analysis of variance with Bonferroni correction was used to compare variables with parametric distribution among the subgroups. To compare three or more variables with non-parametric distribution, we used the Kruskal-Wallis test, followed by Dunn's pairwise tests with Bonferroni correction. Pearson's chi-square test was used to compare differences among proportions. We used the Statistical Package for the Social Sciences (SPSS) v. 20.0, for statistical analysis, and the significance level was set at 5\%. The functionality and QoL outcomes were controlled for age, using multiple regression analyses, considering the HIV (B) group, which presented a lower mean age than the other groups, as a reference.

We assessed the internal consistency of SF-36v2 and WHODAS 2.0, using Cronbach's alpha coefficient. We considered values between 0.60 and 0.70 as satisfactory, and values higher than 0.70 as ideal ${ }^{19,20}$.

\section{Ethical approval}

This study was part of the Brazilian Cohort Project on HIV-AIDS (CoBRA); it was approved by the Ethical Review Board (protocol number 1.035.826) and conducted in accordance with the Brazilian National Health Council Resolution 499/12 and the Declaration of Helsinki 2013. All participants signed the informed consent form.

\section{RESULTS}

A total of 136 patients were enrolled in the study: 68 (50.0\%) with HTLV-1 infection, 39 (28.7\%) with HIV infection, and 29 (21.3\%) with HIV-HTLV-1 coinfection. The mean age of the patients was $49.72 \pm 12.13$ years for all groups, and $52.72 \pm 11.78$, $41.41 \pm 10.30$, and $53.86 \pm 9.84$ years for the HTLV-1, HIV, and HIV-HTLV-1 coinfection group. Table 1 shows the demographic and clinical characteristics of the study groups. Most patients were female (57.4\%), African Brazilian (47.8\%), married or in a stable relationship (53.7\%), had $\geq 9$ years of schooling (63.2\%), and had an income of $<$ one minimum wage (55.9\%). Most (77.9\%) of the individuals were sedentary (23.5\% were obese) and presented with severe comorbidities $(52.2 \%)$, as measured by the Charlson comorbidity index. Marital status, years of education, family income, physical activity level, and BMI were significantly different between the groups (Table 1).

Table 2 shows the pain and functional outcomes of Groups A (HTLV-1), B (HIV), and C (HIV-HTLV-1). The scores for handgrip strength, TUG test, and BBS were poorer for Groups $\mathrm{A}$ and $\mathrm{C}$ than for Group B $(\mathrm{P}<0.05)$. Groups B and $\mathrm{C}$ did not show differences in BPI severity, BPI interference, and 5MWT. The BPI severity of Group A was significantly different from that of the other groups. All the WHODAS 2.0 scores were systematically lower for Group B (HIV) than for the other groups. The Group B presented better functionality than Groups A and C $(\mathrm{P}<0.05)$, except in the "Life Activity" domain, which did not differ between the three groups. The mean scores of the functional outcomes, when controlled for age in the multiple regression analyses, were poorer for Group A (BPI severity, handgrip strength, TUG, BBS, and 5MWT) than for the other groups. The variable BPI interference, when adjusted for age, was significantly different for Group A $(P=0.007)$ as compared to the other groups. The mean scores on the WHODAS 2.0, adjusted for age, were higher and poorer for Group C than for the other groups.

Table 3 shows the scores on the SF-36 v2 domains according to group. Differences were observed between Groups A and C as compared with Group B in physical functioning, bodily pain, and social functioning domains. Group $\mathrm{C}$ did not show significant differences compared with Group B in general health, vitality, physical functioning domains, and PCS. In particular, the scores for the emotional domain did not differ among the three study groups. The mean HRQoL scores, when adjusted for age in the multiple regression analyses, were poorer for Groups $\mathrm{A}$ and $\mathrm{C}$ than for Group B. The MCS, adjusted for age, was significantly different for Group $\mathrm{C}$ as compared to the other groups $(\mathrm{P}=0.009)$.

Grip strength, 5MWT, TUG test, and BBS scores were higher for the Group A that for the others. Further, 25\% of the patients in Group A presented with dynapenia, 39.7\% had a high risk of falling based on the TUG scores, and $28.7 \%$ had slow walking speed and impaired balance based on the 5MWT and BBS scores, respectively.

The Cronbach's alpha coefficients were 0.892 and 0.896 for the SF-36v2 and WHODAS 2.0, respectively. The Bartlett sphericity test was significant $(\mathrm{P}<0.001)$ for both instruments. All domains of the WHODAS 2.0 and SF-36v2 showed satisfactory $(>0.60)$ or ideal (>0.7) Cronbach's alpha values, except for social functioning (Table 4).

\section{DISCUSSION}

We found that both functioning and HRQoL were poorer for the HTLV groups (mono- and coinfection) than for the group with HIV monoinfection. The patients with HIV-HTLV-1 coinfection and HTLV-1 infection also reported having more difficulty performing their daily activities than those with HIV infection. Activity limitations and participation restrictions were common among patients with HIV-HTLV-1 coinfection.

Currently, HIV is considered a chronic, controllable infection, and the life expectancy of this patient group is close to that of the general population ${ }^{21}$. In contrast, despite HTLV-1 being the first identified virus to cause human retroviral infection, there is no effective treatment for the infection. Although most patients with HTLV-1 infection remain asymptomatic, those who develop ATLL or HAM/TSP are likely to have poor clinical outcomes/survival rates. Our data suggest that HIV-HTLV-1 infection has a negative effect on HRQoL and functionality.

There is some evidence of the underlying biological mechanisms linking retroviral infections to poor functioning. HIV and HTLV-1related neuronal damage leads to structural and functional changes in the brain, which can cause a wide range of impairments ${ }^{22,23}$. HTLV-1 is associated with muscle inflammation. Similarly, polymyositis and inclusion body myositis are associated with retroviral infections and are frequently observed in patients infected with HTLV-1. Myopathy can also affect patients irrespective of the presence of other neurological manifestations ${ }^{24,25}$. Muscle abnormalities that may impair the muscle's ability to extract or utilize oxygen during exercise can also be associated with physical limitations in patients with HIV infection ${ }^{26,27}$. 
TABLE 1: Demographic and clinical characteristics of patients with HTLV-1 $(n=68)$, HIV $(n=39)$, and HIV-HTLV-1 $(n=29)$ coinfection treated at the HIV outpatient Clinic, Salvador/Bahia, Brazil, 2017-2018.

\begin{tabular}{|c|c|c|c|c|c|c|}
\hline \multirow{2}{*}{ Demographic and clinical characteristics } & \multicolumn{2}{|c|}{ HTLV-1 } & \multicolumn{2}{|c|}{ HIV } & \multicolumn{2}{|c|}{ HIV-HTLV-1 } \\
\hline & $\mathbf{N}$ & $\%$ & $\mathbf{N}$ & $\%$ & $\mathbf{N}$ & $\%$ \\
\hline Female & 47 & 69.1 & 18 & 46.2 & 13 & 44. \\
\hline
\end{tabular}

Race/Ethnicity

African Brazilian

Mulatto

Caucasian

Marital status

Single

Married/stable relationship

$<9$ years

$\geq 9$ years

Family income (minimal wages)*

$<1 \mathrm{MW}$

$\geq 1 \mathrm{MW}$

Current smoker

Yes

Active/Irregularly Active

60

8

Body mass index $\left(\mathrm{kg} / \mathrm{m}^{2}\right)$

$<25$ - Underweight

25-29 - Normal weight

$\geq 30$ - Obese

Charlson's comorbidity index*

No

Mild

Moderate

Severe

4

9

21

34
24

44

25

4

5.9

47.1

28

88.2

11.8
19

25

24
48.5

38.2

13.2

35.3

64.7

36.8

63.2

58.8

41.2

24

6

15.4

71.8

66.7

31.0

51.3

38.5

10.3

35.3
27.9

36.8
41.0

20.5

69.2

30.8

20.5

79.5

38.5

61.5

$$
4
$$

5.9

4

10.3

10

25.6

12.8

51.3
38.5

8

72.4

27.6

20.7

69.0

69.0

13

37.9

48.3

13.8

3.4
20

5

*Family income (Minimal Wages): 284.6 USD **Charlson's Comorbidity Index. 
TABLE 2: Pain and functionality in individuals with HTLV-1 $(n=68)$, HIV $(n=39)$, and HIV-HTLV-1 $(n=29)$ coinfection treated at the HIV outpatient Clinic, Salvador/ Bahia, Brazil, 2017-2018.

\begin{tabular}{|c|c|c|c|c|c|c|c|}
\hline \multirow[b]{2}{*}{ Variable } & \multicolumn{3}{|l|}{ Groups } & \multicolumn{4}{|c|}{$P$ value for Bonferroni correction } \\
\hline & $\begin{array}{c}\text { HTLV-1 (A) } \\
\text { HIV (B) } \\
\text { HIV-HTLV-1 (C) }\end{array}$ & Mean \pm SD & $\begin{array}{l}\text { ANOVA } \\
P \text { value }\end{array}$ & $\begin{array}{l}\text { A vs. } B \\
P \text { value }\end{array}$ & $\begin{array}{l}B \text { vs. C } \\
P \text { value }\end{array}$ & $\begin{array}{l}\text { A vs. C } \\
\text { P value }\end{array}$ & $\begin{array}{c}\text { Multiple } \\
\text { regression } \\
\text { of variables } \\
\text { adjusted by age } \\
\text { and group } \\
\mathrm{P} \text { value }\end{array}$ \\
\hline \multicolumn{8}{|l|}{ PAIN AND FUNCTIONALITY } \\
\hline \multirow[t]{3}{*}{ The Brief Pain Inventory (BPI) Severity } & A & $53.6 \pm 18.9$ & $<0.001^{* *}$ & $<0.001$ & & & $<0.001$ \\
\hline & B & $39.2 \pm 17.6$ & & & 0,322 & & --- \\
\hline & C & $46.2 \pm 14.7$ & & & & 0.190 & 0.100 \\
\hline \multirow[t]{3}{*}{ The Brief Pain Inventory (BPI) Interference } & A & $47.9 \pm 28.3$ & $0.079^{*}$ & --- & & & 0.007 \\
\hline & B & $35.2 \pm 27.9$ & & & --- & & --- \\
\hline & C & $44.7 \pm 25.1$ & & & & --- & 0.061 \\
\hline \multirow[t]{3}{*}{ Handgrip Strength (kg/f) } & A & $22.1 \pm 7.1$ & $<0.001^{* *}$ & $<0.001$ & & & $<0.001$ \\
\hline & B & $29.9 \pm 9.9$ & & & 0.002 & & --- \\
\hline & C & $23.3 \pm 7.0$ & & & & 1,000 & 0.007 \\
\hline \multirow[t]{3}{*}{5 Meter Walk Test (m/s) } & A & $6.8 \pm 2.9$ & $<0.001^{*}$ & $<0.001$ & & & 0.006 \\
\hline & B & $4.9 \pm 1.1$ & & & 0.106 & & --- \\
\hline & C & $5.5 \pm 2.1$ & & & & 0.278 & 0.786 \\
\hline \multirow[t]{3}{*}{ The timed "Up and Go" (TUG) test } & A & $12.8 \pm 6.9$ & $<0.001^{*}$ & $<0.001$ & & & $<0.001$ \\
\hline & B & $8.3 \pm 1.8$ & & & 0.036 & & --- \\
\hline & C & $10.2 \pm 0.8$ & & & & 0.072 & 0.201 \\
\hline \multirow[t]{3}{*}{ The Berg Balance Scale (BBS) } & A & $41.1 \pm 10.4$ & $<0.001^{*}$ & $<0.001$ & & & $<0.001$ \\
\hline & B & $51.5 \pm 0.7$ & & & $<0.001$ & & --- \\
\hline & C & $38.7 \pm 11.7$ & & & & 1.000 & $<0.001$ \\
\hline \multicolumn{8}{|l|}{ WHODAS } \\
\hline \multirow[t]{3}{*}{ Cognition } & A & $33.3 \pm 12.6$ & $0.002^{*}$ & 0.019 & & & 0.107 \\
\hline & B & $27.0 \pm 3.2$ & & & 0.002 & & --- \\
\hline & C & $38.4 \pm 17.6$ & & & & 0,606 & 0.005 \\
\hline \multirow[t]{3}{*}{ Mobility } & A & $54.2 \pm 23.5$ & $<0.001^{*}$ & $<0.001$ & & & $<0.001$ \\
\hline & B & $32.7 \pm 7.4$ & & & $<0.001$ & & --. \\
\hline & C & $51.7 \pm 25.2$ & & & & 1,000 & 0.010 \\
\hline \multirow[t]{3}{*}{ Self-care } & A & $33.8 \pm 11.8$ & $<0.001^{*}$ & $<0.001$ & & & 0.012 \\
\hline & B & $25.6 \pm 2.4$ & & & $<0.001$ & & --- \\
\hline & C & $37.5 \pm 18.9$ & & & & 1.000 & 0.002 \\
\hline \multirow[t]{3}{*}{ Getting along with people } & A & $39.0 \pm 13.4$ & $<0.001^{*}$ & 0.001 & & & 0.072 \\
\hline & B & $29.6 \pm 7.6$ & & & 0.004 & & --- \\
\hline & C & $42.1 \pm 19.3$ & & & & 1.000 & 0.025 \\
\hline \multirow[t]{3}{*}{ Life activities } & A & $29.2 \pm 14.6$ & $0.448^{*}$ & --- & & & 0.866 \\
\hline & B & $27.2 \pm 10.8$ & & & -- & & --- \\
\hline & C & $32.4 \pm 14.9$ & & & & --- & 0.107 \\
\hline \multirow[t]{3}{*}{ Participation } & A & $50.1 \pm 19.1$ & $0.001^{*}$ & 0.005 & & & 0.010 \\
\hline & B & $39.0 \pm 12.0$ & & & 0.001 & & --- \\
\hline & C & $55.4 \pm 21.2$ & & & & 0,788 & 0.001 \\
\hline \multirow[t]{3}{*}{ Overall Score } & A & $39.9 \pm 12.9$ & $<0.001^{*}$ & $<0.001$ & & & 0.004 \\
\hline & B & $30.2 \pm 3.3$ & & & $<0.001$ & & --. \\
\hline & C & $42.91 \pm 16.5$ & & & & 1.000 & 0.001 \\
\hline
\end{tabular}

*One-way non-parametric analysis of variance (ANOVA) (Kruskal-Wallis test). ${ }^{* *}$ One Way ANOVA; HTLV-1 (A), HIV (B), HTLV-1/HIV (C). 
TABLE 3: SF-36v2 domain scores of individuals with HTLV-1 $(n=68)$, HIV $(n=39)$, and HIV-HTLV-1 $(n=29)$ coinfection treated at the HIV outpatient Clinic, Salvador/ Bahia, Brazil, 2017-2018.

\begin{tabular}{|c|c|c|c|c|c|c|c|}
\hline \multirow[b]{2}{*}{ Variable } & \multirow{2}{*}{$\begin{array}{c}\text { Groups } \\
\text { HTLV-1 (A) } \\
\text { HIV (B) } \\
\text { HIV-HTLV-1 (C) }\end{array}$} & \multirow[b]{2}{*}{ Mean \pm SD } & \multirow{2}{*}{$\begin{array}{l}\text { ANOVA } \\
P \text { value }\end{array}$} & \multicolumn{3}{|c|}{ P value for Bonferroni correction } & \multirow{2}{*}{$\begin{array}{c}\text { Multiple } \\
\text { regression of } \\
\text { variables adjusted } \\
\text { by age and group } \\
\mathrm{P} \text { value } \\
\end{array}$} \\
\hline & & & & A vs. $B$ & B vs. C & A vs. C & \\
\hline \multicolumn{8}{|l|}{ SF-36v2 DOMAINS } \\
\hline \multirow[t]{3}{*}{ Physical Functioning (PF) } & A & $38.7 \pm 12.4$ & $<0.001^{*}$ & $<0.001$ & & & $<0.001$ \\
\hline & B & $49.5 \pm 8.5$ & & & 0.433 & & --- \\
\hline & C & $45.0 \pm 11.1$ & & & & 0.109 & 0.288 \\
\hline \multirow[t]{3}{*}{ Role Physical (RP) } & A & $41.4 \pm 11.4$ & $0.036^{*}$ & 0.114 & & & 0.059 \\
\hline & B & $46 ; 4 \pm 9.8$ & & & 0.050 & & --- \\
\hline & C & $39.7 \pm 11.0$ & & & & 1.000 & 0.034 \\
\hline \multirow[t]{3}{*}{ Bodily Pain (BP) } & A & $38.6 \pm 7.8$ & $<0.001^{*}$ & $<0.001$ & & & $<0.001$ \\
\hline & B & $47.1 \pm 10.3$ & & & 0.029 & & --- \\
\hline & C & $40.4 \pm 9.6$ & & & & 1.000 & 0.006 \\
\hline \multirow[t]{3}{*}{ General Health (GH) } & A & $41.4 \pm 11.4$ & $0.045^{* *}$ & 0.045 & & & 0.006 \\
\hline & B & $47.0 \pm 11.9$ & & & 1.000 & & --- \\
\hline & C & $44.7 \pm 10.0$ & & & & 0.574 & 0.213 \\
\hline \multirow[t]{3}{*}{ Vitality (VT) } & A & $41.6 \pm 11.4$ & $0.001^{*}$ & 0.001 & & & $<0.001$ \\
\hline & B & $49.4 \pm 9.2$ & & & 0.356 & & --- \\
\hline & C & $45.3 \pm 7.8$ & & & & 0.291 & 0.046 \\
\hline \multirow[t]{3}{*}{ Social Functioning (SF) } & A & $42.2 \pm 10.2$ & $0.024^{*}$ & 0.049 & & & 0.065 \\
\hline & B & $46.8 \pm 10.3$ & & & 0.055 & & --- \\
\hline & C & $41.4 \pm 8.7$ & & & & 1.000 & 0.075 \\
\hline \multirow[t]{3}{*}{ Role Emotional (RE) } & A & $41.9 \pm 12.3$ & $0.209^{*}$ & --- & & & 0.989 \\
\hline & B & $41.7 \pm 12.9$ & & & --- & & --- \\
\hline & C & $37.0 \pm 13.6$ & & & & --- & 0.135 \\
\hline \multirow[t]{3}{*}{ Mental Health $(\mathrm{MH})$} & A & $41.5 \pm 10.5$ & $0.011^{*}$ & 0.204 & & & 0.024 \\
\hline & B & $45.2 \pm 10.6$ & & & 0.008 & & --- \\
\hline & C & $37.7 \pm 11.0$ & & & & 0.295 & 0.001 \\
\hline \multirow[t]{3}{*}{$\begin{array}{l}\text { Physical Component Summary } \\
\text { (PCS) }\end{array}$} & A & $39.7 \pm 9.3$ & $<0.001^{* *}$ & $<0.001$ & & & $<0.001$ \\
\hline & B & $49.4 \pm 8.7$ & & & 0.178 & & --- \\
\hline & C & $45.0 \pm 9.4$ & & & & 0.033 & 0.145 \\
\hline \multirow[t]{3}{*}{ Mental Component Summary (MCS) } & A & $43.2 \pm 9.8$ & $0.054^{\star *}$ & --- & & & 0.339 \\
\hline & B & $44.0 \pm 10.4$ & & & --- & & --- \\
\hline & C & $38.4 \pm 10.6$ & & & & --- & 0.009 \\
\hline
\end{tabular}

*One-way non-parametric analysis of variance (ANOVA) (Kruskal-Wallis test). ${ }^{*}$ One Way ANOVA; HTLV-1 (A), HIV (B), HIV-HTLV-1 (C). 
TABLE 4: Internal consistency of each dimension of the SF-36 v2 and WHODAS 2.0.

\begin{tabular}{|c|c|c|}
\hline Domains SF-36 v2 & Number of items & Cronbach's alpha coefficient \\
\hline Physical functioning & 10 & 0.91 \\
\hline Role-physical & 4 & 0.91 \\
\hline Bodily pain & 2 & 0.62 \\
\hline General health & 5 & 0.65 \\
\hline Vitality & 4 & 0.62 \\
\hline Social functioning & 2 & 0.40 \\
\hline Role emotional & 3 & 0.89 \\
\hline Mental health & 5 & 0.68 \\
\hline \multicolumn{3}{|l|}{ Domains WHODAS 2.0} \\
\hline Cognition & 6 & 0.84 \\
\hline Mobility & 5 & 0.91 \\
\hline Self-care & 4 & 0.69 \\
\hline Getting along & 5 & 0.60 \\
\hline Life activities & 4 & 0.92 \\
\hline Participation & 8 & 0.97 \\
\hline
\end{tabular}

SF-36 v2: 36-item Short-Form Health Survey; WHODAS 2.0: World Health Organization Disability Assessment Schedule.

Muscle strength, gait speed, mobility, and greater physical activity are associated with increased QoL ${ }^{28,29}$. In addition, self-selected gait speed is a strong predictor of loss of independence, disability, and mortality ${ }^{30,31}$. There is also a strong association between QoL and gait speed ${ }^{29,32}$.

There were some limitations to our study. First, the small sample size limits the generalizability of the results. However, there is scarce information on the functioning of populations infected with HTLV-1, especially in cases of coinfection. The strength of our study is that the outcomes included in our analysis were related to the prognosis of patients with chronic diseases. In addition, QoL is a very important outcome in studies of patients with retroviral infections ${ }^{33}$. To the best of our knowledge, this is the first study to compare the functioning and HRQoL of patients with HTLV-1 infection, HIV infection, and HIV-HTLV-1 coinfection.

Our results provide preliminary evidence showing a decrease in HRQoL and functioning in patients with HIV-HTLV-1 coinfection and provide a rationale for the implementation of strategies to mitigate these effects.

\section{CONCLUSIONS}

Compared to patients with HIV infection, those with HIVHTLV-1 coinfection and HTLV-1 infection had poor functionality and HRQoL. HTLV-1 monoinfection or in combination with HIV can lead to poor clinical outcomes.

\section{ACKNOWLEDGMENTS}

Universidade Federal da Bahia.

\section{FINANCIAL SUPPORT}

This study was financed in part by the Coordenação de Aperfeiçoamento de Pessoal de Nível Superior - Brasil (CAPES) - Finance Code 001 and by the Conselho Nacional para o Desenvolvimento Científico e Tecnológico (CNPq), Grant \#406129/2016-9.

\section{AUTHORS' CONTRIBUTION}

CSCM: Conception and design of the study, Acquisition of data, Analysis and interpretation of data, and Final approval of the version to be submitted; LLK: Conception and design of the study, Acquisition of data, Analysis and interpretation of data, Final approval of the version to be submitted; CB: Conception and design of the study, Drafting the article, Final approval of the version to be submitted; MGN: Conception and design of the study, Analysis and interpretation of data, Drafting the article, and Final approval of the version to be submitted.

\section{CONFLICT OF INTEREST}

The authors declare that there is no conflict of interest.

\section{ORCID}

Cleyde Sheyla Chachaqui Marconi: 0000-0003-0435-7288

Liliane Lins-Kusterer: 0000-0003-3736-0002

Carlos Brites: 0000-0002-4673-6991

Mansueto Gomes-Neto: 0000-0002-0717-9694 


\section{REFERENCES}

1. Proietti FA, Carneiro-Proietti AB, Catalan-Soares BC, Murphy EL. Global epidemiology of HTLV-I infection and associated diseases. Oncogene. 2005;24(39):6058-68. doi:10.1038/sj.onc.1208968.

2. Brites C, Sampalo J, Oliveira A. HIV/human T-cell lymphotropic virus coinfection revisited: impact on AIDS progression. AIDS Rev. 2009;11(1):8-16.

3. Beilke MA. Retroviral coinfections: HIV and HTLV: taking stock of more than a quarter century of research. AIDS Res Hum Retroviruses. 2012;28(2):139-47. doi:10.1089/AID.2011.0342.

4. Bahia F, Novais V, Evans J, Le Marchand C, Netto E, Page K, et al. The impact of human T-cell lymphotropic virus I infection on clinical and immunologic outcomes in patients coinfected with HIV and hepatitis $\mathrm{C}$ virus. J Acquir Immune Defic Syndr. 2011;57 Suppl 3(03):S202-7. doi: 10.1097/QAI.0b013e31821e9a1e.

5. Romanelli LC, Caramelli P, Proietti AB. Human T cell lymphotropic virus (HTLV-1): when to suspect infection?. Rev Assoc Med Bras. 2010;56(3):340-7. doi:10.1590/s0104-42302010000300021.

6. Lédo AP, Rodriguez-Prieto I, Lins L, Neto MG, Brites C. Association between health-related quality of life and physical functioning in antiretroviral-naive HIV-infected patients. Open AIDS J. 2018;12:11725. doi: $10.2174 / 1874613601812010117$.

7. Galvão-Castro AV, Boa-Sorte N, Kruschewsky RA, Grassi MF, GalvãoCastro B. Impact of depression on quality of life in people living with human T cell lymphotropic virus type 1 (HTLV-1) in Salvador, Brazil. Qual Life Res. 2012;21(9):1545-50. doi:10.1007/s11136-011-0066-6.

8. San-Martin DL, Santos DN, Baptista AF. Pain prevalence, characteristics and associated factors in human T-cell lymphotropic virus type 1 infected patients: a systematic review of the literature. Braz J Infect Dis. 2016;20(6):592-8. doi:10.1016/j.bjid.2016.08.013.

9. Gomes Neto M, Conceição CS, Ogalha C, Brites C. Aerobic capacity and health-related quality of life in adults HIV-infected patients with and without lipodystrophy. Braz J Infect Dis. 2016;20(1):76-80. doi: 10.1016/j.bjid.2015.11.001.

10. Beilke MA, Theall KP, O'Brien M, Clayton JL, Benjamin SM, Winsor EL, et al. Clinical outcomes and disease progression among patients coinfected with HIV and human T lymphotropic virus types 1 and 2 . Clin Infect Dis. 2004;39(2):256-263. doi: 10.1086/422146.

11. Üstün TB, Kostanjsek N, Chatterji S, Rehm J. Measuring health and disability: manual for WHO disability assessment schedule WHODAS 2.0. Geneva, Switzerland: World Health Organization; 2010.

12. Charlson ME, Pompei P, Ales KL, MacKenzie CR. A new method of classifying prognostic comorbidity in longitudinal studies: development and validation. J Chronic Dis. 1987;40(5):373-383.

13. Mathiowetz V, Weber K, Volland G, Kashman N. Reliability and validity of grip and pinch strength evaluations. J Hand Surg Am. 1984;9(2):222226. Doi:10.1016/S0363-5023(84)80146-X.

14. Berg K, Wood-Dauphinée S, Williams JI, Gayton D. Measuring balance in the elderly: preliminary development of an instrument. Physiotherapy Canada. 1989;41:304-311.

15. Wilson CM, Kostsuca SR, Boura JA. Utilization of a 5-meter walk test in evaluating self-selected gait speed during preoperative screening of patients scheduled for cardiac surgery. Cardiopulm Phys Ther J. 2013;24(3):36-43.

16. Podsiadlo D, Richardson S. The timed "up \& go": a test of basic functional mobility for frail elderly persons. J Am Geriatr Soc. 1991;39(2):142-148.
17. Lins-Kusterer L, Valdelamar J, Aguiar CVN, Menezes MS, Netto EM, Brites C. Validity and reliability of the 36 -item short form health survey questionnaire version 2 among people living with HIV in Brazil. Braz J Infect Dis. 2019;23(5):313-321. doi:10.1016/j.bjid.2019.08.001.

18. World Health Organization. International classification of functioning, disability and health (ICF). Geneva: World Health Organization; 2001.

19. Streiner DL. Starting at the beginning: an introduction to coefficient alpha and internal consistency. J Pers Assess. 2003;80:99-103.

20. Nounally JC, Bernstein IH. Psychometric theory. 3rd New York: McGraw-Hill; 1994.

21. Deeks SG, Lewin SR, Havlir DV. The end of AIDS: HIV infection as a chronic disease. Lancet. 2013;382:1525-1533. DOI: 10.1016/S01406736(13)61809-7

22. Araujo AQC, Wedemann D. HTLV-1 Associated neurological complex. What is hidden below the water?. AIDS Rev. 2019;21(4):211-217. doi:10.24875/AIDSRev.19000108.

23. Nixon SA, Hanass-Hancock J, Whiteside A, Barnett T. The increasing chronicity of HIV in sub-Saharan Africa: rethinking "HIV as a longwave event" in the era of widespread access to ART. Glob Health 2011;7:41. doi: 10.1186/1744-8603-7-41.

24. Gilbert DT, Morgan O, Smikle MF, Simeon D, Barton EN. HTLV1 associated polymyositis in Jamaica. Acta Neurol Scand. 2001;104: 101-104.

25. Desdouits M, Cassar O, Maisonobe T, Desrames A, Aouba A, Hermine $\mathrm{O}$, et al. HTLV-1-associated inflammatory myopathies: low proviral load and moderate inflammation in 13 patients from West Indies and West Africa. J Clin Virol. 2013;57:70-76.

26. Raso V, Shephard RJ, Casseb J, Duarte AJ, Silva PR, Greve JM. Association between muscle strength and the cardiopulmonary status of individuals living with HIV/AIDS.Clinics (Sao Paulo). 2013;68: 359-364.

27. Gomes-Neto M, Rodriguez I, Lédo AP, Vieira JPB, Brites C. Muscle Strength and Aerobic Capacity in HIV-Infected Patients: A Systematic Review and Meta-Analysis. J Acquir Immune Defic Syndr. 2018;79(4):491-500. doi: 10.1097/QAI.0000000000001835.

28. Erlandson KM, Allshouse AA, Jankowski CM, Mawhinney S, Kohrt WM, Campbell TB. Relationship of physical function and quality of life among persons aging with HIV infection. AIDS. 2014;2:1939-1943.

29. Balderson BH, Grothaus L, Harrison RG, McCoy K, Mahoney C, Catz $\mathrm{S}$. Chronic illness burden and quality of life in an aging HIV population. AIDS Care. 2013;25:451-458.

30. White DK, Neogi T, Nevitt MC, Peloquin CE, Zhu Y, Boudreau RM, et al. Trajectories of gait speed predict mortality in well-functioning older adults: the Health, Aging and Body Composition study. J Gerontol A Biol Sci Med Sci. 2013;68:456-464.

31. Vestergaard S, Patel KV, Walkup MP, Pahor M, Marsh AP, Espeland MA, et al. Stopping to rest during a 400-meter walk and incident mobility disability in older persons with functional limitations. J Am Geriatr Soc. 2009;57:260-265.

32. Emlet CA, Fredriksen-Goldsen KI, Kim HJ. Risk and protective factors associated with health-related quality of life among older gay and bisexual men living with HIV disease. Gerontologist. 2013;53:963-972.

33. Gakhar H, Kamali A, Holodniy M. Health-related quality of life assessment after antiretroviral therapy: a review of the literature. Drugs. 2013;73(7):651-72. doi: 10.1007/s40265-013-0040-4. 